Saudi Journal of Medicine

Abbreviated Key Title: Saudi J Med ISSN 2518-3389 (Print) |ISSN 2518-3397 (Online)

\title{
Platelet Transfusion: Experience of The Avicenna Military Hospital in Marrakech
}

\author{
Beddou G* ${ }^{*}$, Amaddah R, Skali H, Yahyaoui H, Benjelloun I, Chakour M, Ait Ameur M \\ Biological Hematology Department, Avicene Military Hospital in Marrakech, Morocco
}

DOI: $10.36348 /$ sjm.2020.v05i01.012 $\quad$ | Received: 20.01.2020 | Accepted: 27.01.2020 | Published: 30.01 .2020

*Corresponding author: Beddou Ghita

Abstract

The platelet transfusion must necessarily meet the concepts of safety and transfusion threshold. Asking for an indication and prescribing a platelet transfusion remains complex and must take into account an increasing number of parameters (indication, quantitative and qualitative choice of product, the notion of the threshold, clinical situation and finally the cost).The study that we conducted is a retrospective descriptive and analytical study, over a period of 2 years, from January 2017 to December 2018, with the objective of studying the stages of preparation of platelet concentrates, their indications, their complications, and to report on the experience of platelet transfusion within the Avicenne Military Hospital in Marrakech. During this period, 777 platelet concentrates (753 SPC and 24 APC) were delivered to 107 patients. The department of internal medicine where a hematology-oncology unit is located is the most demanding department. The average of transfused bags is 7.5 bags/patient. The indication was curative in $55 \%$, dominated by thrombocytopenia of central origin. The pre-transfusion platelet count was $5410^{3} / \mathrm{mm}^{3}$ for standard platelet concentrates (SPC) and $2710^{3} / \mathrm{mm}^{3}$ for apheresis platelet concentrates (APC). Finally, the platelet transfusion yield was greater than $20 \%$ in $50 \%$ of the cases. These data make it possible to demonstrate compliance with the indications for platelet transfusion in the most demanding departments, but raise the question of the dose that must be respected in order to improve platelet yield.

Keywords: Platelet transfusion, Standard platelet concentrate, Platelet concentrate, apheresis, Indications, Risks, Platelet yield.

Copyright @ 2020: This is an open-access article distributed under the terms of the Creative Commons Attribution license which permits unrestricted use, distribution, and reproduction in any medium for non-commercial use (NonCommercial, or CC-BY-NC) provided the original author and source are credited.

\section{INTRODUCTION}

The transfusion of platelet concentrates (PC) of human origin is the first line replacement therapy in the management of patients with bleeding syndrome related to platelet damage, or at high risk of bleeding [1]. Unfortunately, there are several obstacles to the use of these concentrates: limited availability, a high price, the need to use specific and restrictive preservation methods, an allergic and infectious risk for the recipient, a risk in certain thrombocytopenia. increase the symptomatology and be deleterious for the patient, a potential ineffectiveness [2]... It is therefore essential for any practitioner to limit himself to formal indications and to carefully weigh the balance of benefits and risks for the patient before any transfusion. The aim of our work is to report the platelet transfusion practice of the Blood Transfusion Center (BTC) of the Avicenne Military Hospital (AMH) in Marrakech and to compare it with data from the literature.

\section{MATERIALS AND METHODS}

This is a retrospective descriptive and analytical study of the experience of the Avicenne Military Hospital (AMH) in Marrakech about the transfusion of platelets over 2 years, from January 2017 to December 2018 obeying the exploitation sheet (annex I). We included all living and deceased patients who received a platelet transfusion during the study period, but patients who received an external platelet transfusion were excluded from our study.

\section{The transfused platelets were prepared by two methods}

Standard platelet concentrate (SPC) : The donation is collected 3 times a month. A volume of $400 \mathrm{ML}$ is collected from subjects between 18 and 58 years of age in sterile triple bags, whose whole blood collection bag contains an anticoagulant solution. The plasma is extracted in the number 1 satellite bag (dry). 
The satellite bag number 2 contains an additive solution intended to be transferred to the main pocket containing the erythrocyte concentrate. We have an empty pocket which will be reserved for the storage of the SPC. Whole blood is then centrifuged at $4000 \mathrm{rpm}$ for $10 \mathrm{~min}$ at $22{ }^{\circ} \mathrm{C}$ to obtain concentrated red blood cells (CRC) and platelet-rich plasma (PRP), The separation uses manual presses to extract the plasma from the main whole blood pocket then the tubing is welded perpendicular to the jaws and the pocket of the globular concentrate (GC) obtained from the other two pockets is separated by exerting a stretch on the weld on the GC side. The previous steps of centrifugation (but this time at $3000 \mathrm{rpm}$ ), separation and welding are repeated to separate the platelet-rich plasma (PRP) into standard platelet concentrate (SPC) and platelet-poor plasma (PPP).

Apheresis platelet concentrate (APC): the donors were selected after a medical examination and a pre-donation biological control. The venous network at the elbow fold is well-chosen to ensure a blood flow of 60 to $80 \mathrm{ml} / \mathrm{min}$. A hemogram is performed to determine the platelet count which must be greater than 200,000 per microliter, in order to have a satisfactory yield, and a hemostasis balance (TP, TCA) with an age range of donors between 18 and 58 years. The separator used in the AMH laboratory is an MCS + discontinuous flow separator from Haemonetics. In order to maintain optimal venous flow, the MCS is equipped with an inflatable cuff, which automatically maintains a predetermined pressure during the sampling cycle.

Each blood donation is subjected to screening tests for infectious diseases transmissible by blood transfusion and Immuno - hematological analyses aimed at determining the $\mathrm{ABO}$ and Rhesus blood group of the donor.

The storage of PC (from apheresis or standard) is carried out by continuous horizontal agitation at room temperature $\left(22 \pm 2^{\circ} \mathrm{C}\right)$ for five with a maximum of seven days [3].

The volume of the PC, the content in blister packs, production date, expiry date, HIV serology HBV HCV Syphilis NEGATIVES and the ABO Rhesus group are recorded in each pocket of APC and SPC by regulatory obligation.

Data were collected from the CTS AMH archives and medical records of patients who received platelet transfusions.
Data entry and analysis was carried out using SPSS version 17 and Microsoft Office Excel 2013 for Windows version 10.0 software.

\section{RESULTS}

Our series involved 3,203 donors, including 3,159 of standard platelet concentrates, or $98.6 \%$, and 44 of platelet concentrates by apheresis or $1.4 \%$.

1,518 SPC donations were in 2017 or $48 \%$ compared to 1,641 were in 2018 or $52 \%$ and 31 APC donations were in 2017 or $71 \%$ compared to 13 in 2018 or $29 \%$.

The average age of patients with a request for a platelet pellet is \pm 49.5 years, with extremes from 19 to 80 years with 37 women or $35 \%$ and 70 men or $65 \%$ with a sex ratio $\mathrm{M} / \mathrm{F}$ of 1,9 with a total of 107 patients

In these 107 requests, 10 were APC type or 9\% against 97 SPC type requests or $91 \%$. During this same period, 777 bags were delivered to the military hospital, of which 753 were SPC or $96 \%$ and 24 were APC or $4 \%$ With an average of \pm 7.5 bags/patient (extremes: $1-14$ ) for the SPC and an average of 3 pockets / patient (extremes: 1-5) and distributed differently depending on the year as we note that in 2018, no APC pocket was delivered due to lack of materials during this period.

\section{The number of bags consumed per month during the period of our study is distributed as follows}

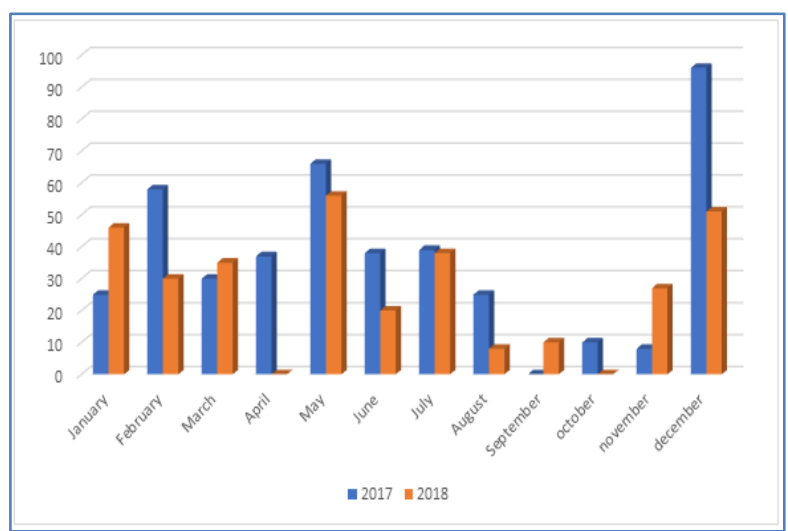

Fig-1: Distribution of platelet pellet pockets delivered per month

The first consumé service of PC within the $\mathrm{AMH}$ is the internal medicine service, where there is a clinical hematology unit with a percentage of $68 \%$ followed by the resuscitation service with a percentage of $15 \%$. Neurosurgery, cardiology services come last with a percentage of $1 \%$. 


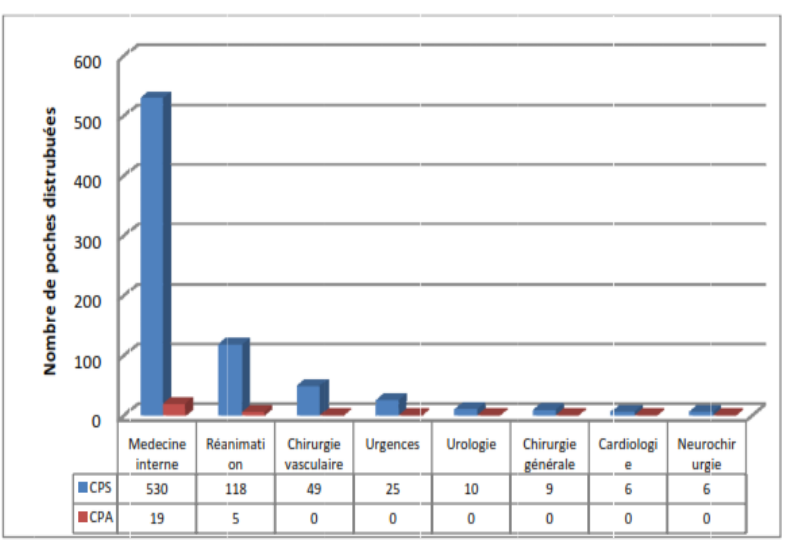

Fig-2: Distribution of the pockets distributed according to the requesting services

The most frequently encountered pathologies are acute leukemias followed by bone marrow aplasia, the table below summarizes the number of PC distributed by pathology.

Table-I: Number of platelet pellets distributed according to the diagnosis

\begin{tabular}{|l|l|}
\hline Diseases & Platelet base \\
\hline Acute leukemia & 16 \\
\hline Myelosuppression & 14 \\
\hline Isolated thrombocytopenia & 10 \\
\hline Pancytopenia & 10 \\
\hline Lymphomas & 7 \\
\hline Solid tumors & 5 \\
\hline Myélodysplasia & 8 \\
\hline Septic shock & 9 \\
\hline Hemorrhagic Shock & 8 \\
\hline Valve replacement & 1 \\
\hline Aortic bypass & 1 \\
\hline Cystectomy & 1 \\
\hline Other & 17 \\
\hline Total & 107 \\
\hline
\end{tabular}

(Other: disseminated intravascular coagulation (DIC-, chronic renal failure, post-operative, stroke, cerebral, idiopathic thrombocytopenic purpura, scleroderma)

In our study $55 \%$ of patients were transfused for curative purposes versus $45 \%$ prophylactically and the mean value of the platelet count in patients was 54 $10^{3} / \mathrm{mm}^{3}$ (extreme 9-60 $10^{3} / \mathrm{mm}^{3}$ ) for SPC and an average of $2710^{3} / \mathrm{mm}^{3}$ (extreme $8-4610^{3} / \mathrm{mm}^{3}$ ) for APC and $27 \%$ of patients were polytransfused.

In our series, the prescriptions were all mentioned by a number of platelet pellets, and no crossmatch sheet was stapled to the file, but also no immediate transfusion reaction was mentioned on the files used.

Of our 80 usable files (80 transfusions of platelet concentrates), it is impossible to calculate the transfusion yield in almost $26 \%$ of cases (21 transfusions). There are several causes for this: - For 12 transfusions, post-transfusion control could not be carried out within 24 hours of the patient's death. - For 9 transfusions, post-transfusion control is not found in the patient's medical records.

En 40 transfusions, i.e. $50 \%$ of the cases, the platelet transfusion provides a yield greater than $20 \%$, therefore satisfactory transfusion efficiency. We can, however, observe that the transfusion yield of $24 \%$ of the patients (19 patients) is lower than $20 \%$, in fact, 5 of these yields are uninterpretable because the transfusions are carried out in patients with hemorrhage. No immediate or delayed incidents or accidents have been recorded in patient medical record.

\section{DISCUSSION}

The interest of platelet transfusion was shown at the beginning of the 20th century by the demonstration of a correlation between platelet count and bleeding time anomaly [4]. Over the past fifteen years, the use of platelets has increased in parallel with the improvement of the treatment of cancers, including hemopathies, and the development of bone marrow transplants. In France, the annual consumption of platelets has increased by more than 30,000 products since 1995 [7].

The problems linked to the contamination of patients with the human immunodeficiency virus and the hepatitis $\mathrm{C}$ virus, during transfusions of labile blood products, have led politicians to question and then regulate the transfusion act. [5-6] The aim of this approach is to establish maximum safety for the patient when a decision is made to transfuse him [8].

In Morocco, this security need is the basis of law no 23-04 of 20 Chaoual 1426 (23 November 2005) amending and completing law no 03-94, as well as decree no 2- 06-303 of 22 Chaoual 1427 ( November 14, 2006) supplementing Decree No. 2-94-20 of 22 Joumada II1416 (November 16, 1995) taken for its application provide for the definition and rules of haemovigilance and the establishment of the transfusion safety committee to the Minister of health.

In our study, and over a period of 2 years 107 patients were programmed for a platelet transfusion, corresponding to 777 bags of PC distributed. In the martinaud study [9] 105 patients were programmed for a platelet transfusion corresponding to 235 bags of PC distributed, in the study by C. Humbrecht and Al [10] 137 were programmed for a platelet transfusion corresponding to $350 \mathrm{PC}$ bags and in the A.BELMEKKI study [11] 429 patients were programmed for a platelet transfusion. We note that in our series the number of bags delivered is high compared to other studies despite the number of patients that gets closer, this can be explained by the predominance of SPC bags (96\%) (Need 6 to 10 bags to 
ensure a transfusion episode) and the low number of $4 \%$ APC pockets distributed.

The average age in our study is 49.5 years, 59.6 years in the study by C. Martinaud [9], and 61.2 years in the study by C. Humbrecht [10] with a predominance of male in our study as well as in these other studies.

The indications for platelet concentrates are peripheral or central thrombocytopenia. Due to their short shelf life, the platelets are transfused daily as needed (flow rate of $10 \mathrm{ml}$. Min-1). The prescription must state the patient's weight, platelet count and indication. In our study, no prescription mentioned the patient's weight, the pre-transfusion platelet count, or the indication for the transfusion. The department of medicine (clinical hematology) is the first applicant for PC with a rate of $69 \%$ where hemopathies constitute the most treated pathologies (thrombocytopenia of central origin). In the study by C. Humbrecht [10] the department of medicine (onco-hematology) was the most demanding with a rate of $64.8 \%$. In C.martinaud's study [9] the medical service was the most demanding with a rate of $58 \%$. In A. BELMEKKI's study [11] the medical service was the most demanding with a rate of $82.2 \%$. We note that the medical service is the most demanding in our study which is identical to the other studies, followed by the resuscitation service except in the study by A. BELMEKKI [11].

The platelet content of a SPC is around 0.5. 10 11. Due to physiological splenic sequestration of approximately $40 \%$ of the transfused platelets, a SPC, therefore, provided $30.10 * 9$ platelets to the circulating blood volume [12]. This contribution induces a theoretical increase in the post-transfusion count of 6 GL-1 in an adult recipient whose total blood volume is 5 L. It is on this theoretical calculation that the recommended dosage is based, first line, 0.5. $10 * 11$ plates for $7 \mathrm{~kg}$ body weight [13]. With the exception of a very small recipient, a mixture of several SPC is necessary for a transfusion act. An APC chosen appropriately for the weight of the recipient alone ensures an effective therapeutic dose. [12] In our study, the average rate of distributed PC bags is 7.2 for all types of PC combined. In the study by C. Humbrecht [10], the average rate of bags of PC distributed is 2.4. And in the study by C.martinaud [9] the average rate of distributed PC bags is 2.2.

We note that in $\mathrm{AMH}, \mathrm{SPC}$ is the most requested $98 \%$, and we must, therefore, use 6 to 10 SPC to obtain the quantity of platelets necessary for a transfusion episode, which explains the high average rate of bags used in our study compared to other studies.
It is recommended to reduce the volume of platelet transfusion. The performance of the platelet transfusion is assessed by a platelet count within 24 hours $[13,14]$. In our study, the platelet perfusion was performed for a curative purpose in $55 \%$ of the cases and for a prophylactic purpose in $45 \%$ of the cases. In the study by C. Humbrecht [10] the platelet perfusion was carried out with a prophylactic aim in $72 \%$ of the cases and curative in $28 \%$ of the cases. In the study by C.martinaud [9] the platelet perfusion was carried out with a prophylactic aim in $47 \%$ of the cases and curative in $53 \%$ of the cases.

We note that our results are close to those of C.martinaud, however, they differ from those of $\mathrm{C}$. Humbrecht. Control of transfusion efficiency: It must be carried out during prophylactic transfusions. An increase in the platelet count is observed during posttransfusion control. The absence of externalized hemorrhage or deglobalization can also constitute a criterion of effectiveness [15].

There is no recommendation regarding the time between transfusion and control. Routinely, counting is often done the day after the transfusion, which probably results in an underestimation of the yield. When interpreting it, it must be taken into account that all of the transfused platelets do not recirculate: around a third of these remain sequestered in the spleen (therefore with a higher rate in splenectomized patients) $[16,17]$.

The transfusion yield should normally be between 0.2 and 0.75 . If it is less than 0.20 , a cause must be sought [18]: A platelet dosage used too low, platelets whose quality is impaired (the yield is higher the shorter the shelf life), a transfusion in a polytransfused patient without any alloimmunization [19], major ABO incompatibility, anti HLA alloimmunization of the recipient [20], presence of infection or fever [21], hemorrhage, drug therapy (heparin, vancomycin) [22], DIC, micro thrombotic angiopathy, veno-occlusive disease [23], or splenectomy [24].

If a low yield is found, the following transfusion should be carried out, avoiding all the parameters explaining a drop in it before concluding with a refractory state. It is then recommended, after having eliminated all the causes already mentioned, not to carry out any more prophylactic transfusion [25].

In our study, in 40 transfusions, i.e. $50 \%$ of the cases, platelet transfusion provides a yield greater than $20 \%$, therefore satisfactory transfusion efficiency. The yield was less than $20 \%$ en $20 \%$ of the cases $(25$ patients): it was 22 SPC and 3 APC. 
Among these 20 platelet concentrates with a platelet transfusion yield of less than $20 \%$, there was an incompatibility of cellular ABO donor/recipient for 10 platelet concentrates. In contrast, there were platelet concentrates with $\mathrm{ABO}$ donor/recipient incompatibility that had a yield greater than or equal to $20 \%$. For 2 PCs with transfusion efficiency lower than $20 \%$, the patients presented a DIC, and for 5 patients, they had an active hemorrhagic syndrome. Our results are similar to those of C. martinaud [9]. The platelet transfusion yield was above $20 \%$ in $59 \%$ of the cases and below the target of $20 \%$ in only $24 \%$ of the cases. In our study, immediate and delayed incidents and accidents were not objectified.

\section{CONCLUSION}

The extension of the indications for intensive treatments in hematology and oncology requires the use of transfusions of platelet concentrates more and more frequently. We must strive to improve existing products and define their indications perfectly to limit side effects and control costs.

The simplest way to access these two goals is to use PC transfusion only in situations where it is necessary. It is in this context that we wanted to make an inventory of this practice in the Avicenne Military Hospital of Marrakech.

However, it is necessary to have a relevant and reproducible criterion apart from stopping a hemorrhage to judge the transfusion efficiency, the calculation of platelet yield is the most relevant criterion with the need to use adequate products. , and in particular, a quantity of compatible ABO platelets, adapted to the weight of the patient.

\section{ANNEX I : THE EXPLOITATION SHEET}

Identity: ...................... Age $\begin{aligned} & \text { Age } \\ & \text { Departmenet: Medecine }\end{aligned}$ Surgery $\quad \square$ resuscitation
Entry dignostic

Transfusion indication :

** Clinical:

Hemorrhagic syndrome:

Hemodynamic instability (vital emergency):

Onco - hematological diseases:

Surgical situation:

Others:

**Biological:

Platelet count:

Type of platelet concentrate:

SPC:

APC:

Number of pockets of platelet concentrate:

ABO grouping:

Rhesus:

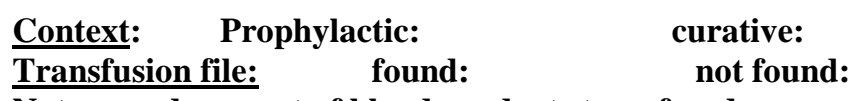

Nature and amount of blood products transfused:

Platelet pellets: APC: SPC: Quantity: .....

Red cell: Quantity: .......

PFC: Quantity: ....

Product bundling transfused ABO Rh:

Ultimate Control bedside: done : not done:

Number of transfusion ........

Transfusion Reaction: yes : no :

Type of transfusion reaction:

\section{Evolution :}

$\begin{array}{ll}\text { Clinical : } & \text { favorable } \\ & \text { Incidents : }\end{array}$

unfavorable

Accidents:

Biologique:

Platelet count

RIA: Reaction of irregular agglutinins:

Done:

not done: 


\section{REFERENCES}

1. Chakroun, T., Abdelkefi, S., Bouslama, M., Houissa, B., Zaier, M., Miled, A., ... \& Yacoub, S. (2008). Complexes leucoplaquettaires en tant que marqueur d'activation dans les concentrés plaquettaires standards. Transfusion clinique et biologique, 15(4), 148-153.

2. Giraud, C., Korach, J. M., Andreu, G., Lacaze, C., \& Vaicle, M. (2002). Applications transfusionnelles et thérapeutiques des techniques d'aphérèse. Transfusion clinique et biologique (Paris), 9(3), 186-228.

3. Handin, R. (1997). Recommandations pour la Pratique Clinique. Indications et contre-indications des transfusions de produits sanguins labiles. Paris: ANAES.

4. Danic, B. Énoncer les conditions d'un don du sang standard et les motifs d'exclusion. Transfusion clinique et biologique, 2005.12(3): p. 287-289.

5. Brahima Amadou, A. (2016). Les concentrés plaquettaires: préparation et contrôle de qualité au CTS de l'HMIMV (Doctoral dissertation).

6. Danic, B. (2009). La collecte du sang et de ses composants en en 2009. Hématologie, 15(5), 336-341.

7. Willaert, B., Mai, M. P. V., \& Caldani, C. (2008). French haemovigilance data on platelet transfusion. Transfusion Medicine and Hemotherapy, 35(2), 118-121.

8. Colin, R., \& Chamouni, P. (1998). Conséquences pratiques de l'application des textes réglementaires liés à la transfusion Sanguine et aux médicaments dérivés du sang. Lett Hepatogastroenterol, 4, 1899.

9. Martinaud, C., Chastagnet, N., Sailliol, A., de Jaureguiberry, J. P., \& Aguilon, P. (2012). Évaluation des pratiques transfusionnelles plaquettaires. Transfusion clinique et biologique, 19(1), 25-31.

10. Humbrecht, C., Somme, S., Renaudier, P., Gross, S., Gachet, C., \& Schlanger, S. (2018). Étude comparative des transfusions de concentrés plaquettaires en Alsace et en Lorraine-Champagne en 2015. Transfusion Clinique et Biologique, 25(3), 179-186.

11. Belemekki, A., Enneffah, L., Khalid, G., Youbi, D., \& Rochdi, J. (2019). Le don de plaquettes par technique d'aphérèse: expérience du centre de transfusion sanguine de l'HMIMV. Transfusion Clinique et Biologique, 26(3), S38.

12. Pindyck, J., Avorn, J., Kuriyan, M., Reed, M., Iqbal, M. J., \& Levine, S. J. (1987). Blood donation by the elderly: clinical and policy considerations. Jama, 257(9), 1186-1188.

13. Danic, B. (2003). La sélection clinique des candidats à un don du sang. Transfusion clinique et biologique, 10(3), 227-233.
14. Vo, T. D., Cowles, J., Heal, J. M., \& Blumberg, N. (2001). Platelet washing to prevent recurrent febrile reactions to leucocyte- reduced transfusions. Transfusion medicine, 11(1), 45-47.

15. De Wildt- Eggen, J., Nauta, S., Schrijver, J. G., van Marwijk Kooy, M., Bins, M., \& Van Prooijen, H. C. (2000). Reactions and platelet increments after transfusion of platelet concentrates in plasma or an additive solution: a prospective, randomized study. Transfusion, 40(4), 398-403.

16. Tissot, J. D., Danic, B., \& Schneider, T. (2015). Transfusion sanguine: en toute sécurité d'approvisionnement. La Presse Médicale, 44(2), 178-188.

17. Tardivel, R., Bois, S., Vignoli, C., Naegelen, C., \& Isola, H. (2009). Automatisation de la préparation des produits sanguins labiles. Transfusion clinique et biologique, 16(2), 175-178.

18. Dohan, S., Dohan, A., Choukroun, J., Diss, A., Simonpieri, A., Girard, M. O., \& Dohan, D. (2005). De l'usage des concentrés plaquettaires autologues en application topique. EMC-Odontologie, 1(2), 141-180.

19. Bierling, P. (2009). Transfusion de concentrés plaquettaires. Transfusion clinique et biologique, 16(2), 190-194.

20. Andreu, G., Vasse, J., Hervé, F., Tardivel, R., \& Semana, G. (2007). Introduction en pratique transfusionnelle des concentrés de plaquettes en solution de conservation: Avantages, inconvénients, et intérêt pour les patients. Transfusion clinique et biologique, 14(1), 100-106.

21. Chamouni, P., Josset, V., Bastit, D., Tavolacci, M. P., Lenain, P., Varin, R., \& Czernichow, P. (2005). Transfusions de concentrés plaquettaires Rhésus incompatible au CHU de Rouen: pratiques et conséquences. Transfusion clinique et biologique, 12(4), 306-312.

22. Nguyen, K. A., Cognasse, F., Boussoulade, F., Fabrigli, P., Odent-Malaure, H., Absi, L., ... \& Garraud, O. (2013). Les concentrés plaquettaires en transfusion sanguine: préparation, normes et principes de sécurité pour une meilleure tolérance et l'éviction d'effets indésirables. Hématologie, 19(6), 371-382.

23. HAS, A. (2015). Recommandation de bonne pratique: transfusion de plaquettes: produits, indications.

24. Swiech, A., \& Ausset, S. (2016). Les produits sanguins labiles en 2016. Médecine Intensive Réanimation, 25(5), 475-483.

25. Ramanathan, R. K., Triulzi, D. J., \& Logan, T. F. (1997). Transfusion- related acute lung injury following random donor platelet transfusion: a report of two cases. Vox sanguinis, 73(1), 43-45. 